\title{
Validation of Non-invasive Method for Electrocardiogram Recording in Mouse using Lead II
}

\author{
Myung Jun Kim ${ }^{1}$, Ji Eun Lim² and Bermseok $\mathrm{Oh}^{1,2, \uparrow}$ \\ ${ }^{I}$ Department of Biomedical Science, Graduate School, Kyung Hee University, Seoul 02447, Korea \\ ${ }^{2}$ Department of Biochemistry and Molecular Biology, School of Medicine, \\ Kyung Hee University, Seoul 02447, Korea
}

\begin{abstract}
Electrocardiogram measures the electric impulses generated by the heart during its cycle. Recently genome-wide association studies on electrocardiogram traits revealed many relevant genetic loci. Therefore, these findings need to be validated and investigated to determine the underlying mechanisms using mouse models. Invasive radiotelemetry has been widely used to record the electrocardiogram in mice because it has several advantages over non-invasive measurements. However, radiotelemetry is expensive and requires complicated surgery. On the other hand, a non-invasive method using 3 electrodes (one for earth) for lead II is easy to establish and allows for rapid measurement. In this study, eleven mice were measured with this non-invasive method and no statistical difference among them was found in any ECG measurements. In addition, repeat measurement in the same mouse was performed in 9 sets of experiment and the results indicated that non-invasive method was reliable for reproducibility. Further it was shown that measurements for 1, 5, 10, and 15 minutes were not different so that a short recording such as 5 minutes was enough to estimate the ECG values including heart rate. Further this method was validated by measuring the ECG of Balb/c and FVB that were previously shown to differ in ECG values by radiotelemetry. Significant differences were found in heart rate, PR interval and corrected QT interval between these mouse strains. This study partially proved that non-invasive method also could provide the accuracy and reproducibility. Based on these results, the non-invasive ECG recordings of lead II is recommended as a useful method for quick test in mouse model.
\end{abstract}

Key Words: Electrocardiogram, Non-invasive method, Mouse, Validation

\section{INTRODUCTION}

Electrocardiogram (ECG) measures the electrical impulses generated by the heart during its cycle. Although these signals are weak, they can be captured at the surface of the skin (Goldbarg et al., 1968). ECG can reveal dispropor-

\footnotetext{
*Received: June 4, 2015 / Revised: September 30, 2015

Accepted: September 30, 2015

${ }^{\dagger}$ Corresponding author: Bermseok Oh. Department of Biochemistry and Molecular Biology, School of Medicine, Kyung Hee University, \#26 Kyunghee-daero, Dongdaemun-gu, Seoul 02447, Korea.

Tel: +82-2-961-0617, Fax: +82-2-6008-0647

e-mail: ohbs@khu.ac.kr

C The Korean Society for Biomedical Laboratory Sciences. All rights reserved.
}

tionate or enlarged atriums or ventricles as well as conductivity dysfunctions, cardio medicine testing and pacemaker performance evaluations, aiding in diagnosing a patient's condition or disease (Bigger et al., 1992; Bruell et al., 1962; Janse et al., 1998; Kleiger et al., 1987; Sandercock et al., 2006). ECG reflects the cycle of heart and is comprised of $\mathrm{P}, \mathrm{Q}, \mathrm{R}, \mathrm{S}$, and $\mathrm{T}$ waves. The $\mathrm{P}$ wave is produced by atrial depolarization, the QRS pulses represent ventricular depolarization, and the $\mathrm{T}$ wave represents ventricular repolarization (Goldbarg et al., 1968). Lengthening or shortening of the $\mathrm{P}$ wave causes high blood pressure or acute myocardial infarction, and irregular QRS pulses indicate pre-excitation syndromes. Abnormal $\mathrm{T}$ wave can indicate myocardial 
ischemia or myocarditis (de Bruyne et al., 1999; Montanez et al., 2004).

Factors that affect heart functions may include environmental causes, but genetic factors also seem significant. Recently, genome-wide association studies have identified many genetic loci that are associated with PR interval (Holm et al., 2010; Hong et al., 2014; Pfeufer et al., 2010), QRS duration (Holm et al., 2010; Hong et al., 2014; Sotoodehnia et al., 2010), and QT interval (Kim et al., 2012; Newton-Cheh et al., 2009; Pfeufer et al., 2009). Therefore, it demands to validate these genetic risks of ECG and investigate the underlying mechanisms using mouse models. ECGs have been obtained by invasive and non-invasive techniques from mice (Zhao et al., 2011). A most widely used invasive method is conducted by transplanting a remote measurement device, called radiotelemetry. However, this method involves an expensive measurement device, and adequate recovery period is needed after the transmitter is implanted in mice (Lorenz, 2002; Uechi et al., 1998). In contrast, the non-invasive procedure using ECG electrodes inserted under the skin of left-leg and right arm in mouse (lead II) is straightforward, so the ECG can be taken quickly and easily.

The anesthesia is required in the non-invasive method during contacting ECG electrodes and measuring ECG (Gao et al., 2011; Zhao et al., 2011). Various anesthetics can affect the heart activity and thus adequate selection is critical (Odashima et al., 2007; Stypmann, 2007; Yang et al., 1999). Ketamine or xylazine administered via intraperitoneal or intramuscular injections affects the cardiovascular system and increases blood pressure, heart rate, and cardiac output (Erhardt et al., 1984; Hart et al., 2001; Xu et al., 2007). However, compared to ketamine or xylazie, avertin $(2,2,2$ tribromoethanol) achieves a stable anesthesia state faster and is appropriate for experiments with short durations. Furthermore, it is not classified as a narcotic drug so it is widely available and is used on small animals for genetic studies (Hart et al., 2001; Roth et al., 2002). In this study, a non-invasive ECG measurement method using three probes including one earth for lead II was tested for stability during the recording and reproducibility in the same mice anesthetized by avertin. Further this method was validated by measuring the ECG of two different mouse strains, Balb/c and FVB that were previously shown to be different in ECG values by radiotelemetry (Shah et al., 2010).

\section{MATERIALS AND METHODS}

\section{Animals and housing conditions}

Balb/c mice (Japan SLC, Inc., Shizuoka, Japan) and FVB/ NJ mice (Jackson Laboratory, Bar Harbor, ME, USA) were bred in a pathogen-free facility and male mice at age 7 to 9 weeks with body weights of 20 grams were used. The mice were maintained on a 12-hr light/dark cycle at constant temperature with free access to food and water. Every effort was made to minimize the number of animals that was used and their suffering per the Committee for the Care and Use of Laboratory Animals, College of Pharmacy, Kyung Hee University (KHP-2010-04-06).

\section{Anesthesia}

The mice were anesthetized with avertin. The standard dose was $0.02 \mathrm{ml}$ of working avertin solution per gram body weight, and the working solution was made by diluting a stock solution (10 g 2,2,2 tribromoethanol, dissolved in $10 \mathrm{ml}$ tertiary amyl alcohol) 40 -fold in $0.9 \% \mathrm{NaCl}$. 2,2,2 tribromoethanol (97\%) was purchased from Sigma-Aldrich (St. Louis, MO). Mouse ECG was measured after 10 minutes of intraperitoneal injection.

\section{ECG measurement and data analysis}

Anesthetized mouse was placed in a supine position. After complete induction of anesthesia $(<3 \mathrm{~min})$, Acupuncture needle $(0.20 \times 15 \mathrm{~mm}$, DongBang Acupuncture, Sungnam, Korea) electrodes were inserted subcutaneously according to the lead II (left foreleg, right foreleg, and left rear leg) ECG scheme (Fig. 1). ECGs were recorded using a PowerLab 8/30 supplemented with an animal BioAmp and analyzed by the LabChart7 software (AD Instruments, Bella Vista, Australia). Each channel was amplified and sampled at a rate of $2 \mathrm{kHz}$ rate and $5 \mathrm{mV}$ range of a high-pass filter setting of $1 \mathrm{~Hz}$. Based on the P wave Standard PR interval is $70 \mathrm{~ms}$ and $10 \mathrm{~ms}$ and up to a maximum when the mouse RT interval $60 \mathrm{~ms}$ exclusion. The average ECG signal was 
(A)

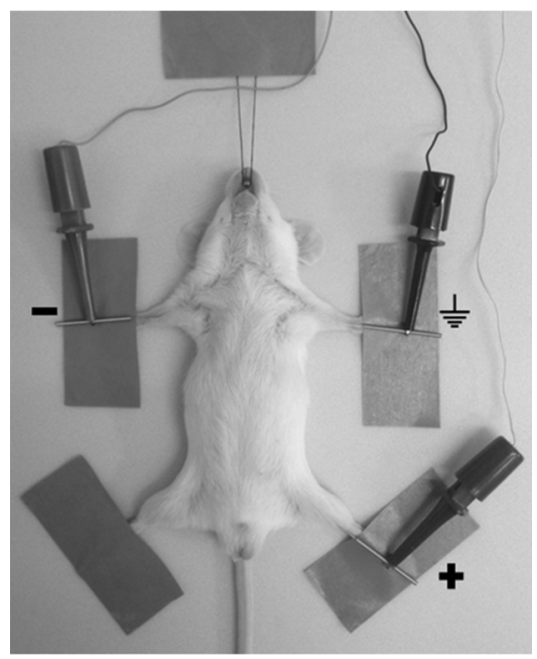

B

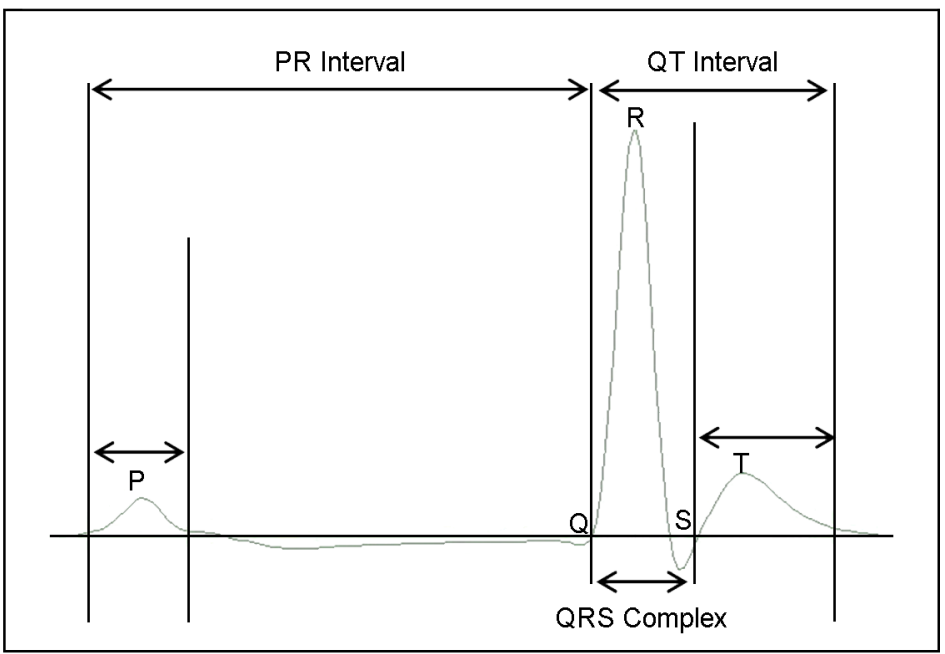

Fig. 1. Mouse ECG measurement system. (A) Acupuncture needle electrodes are inserted subcutaneously according to the lead II (left foreleg, right foreleg, and left rear leg) ECG scheme. (B) Averaging view of ECG from an anesthetized Balb/c mouse.

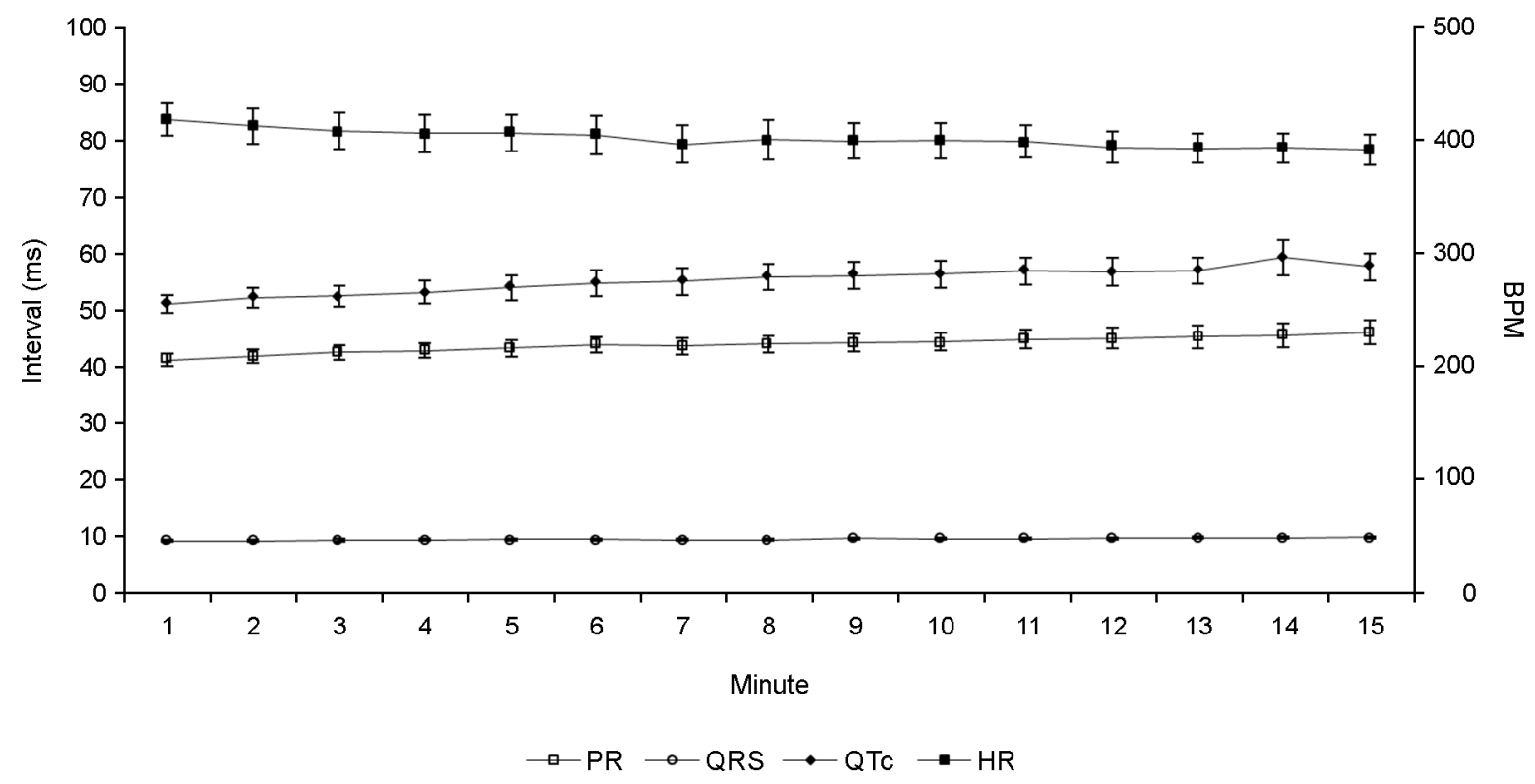

Fig. 2. Results of ECG measurement during 15 minutes. Each symbol represents the average ECG signal of 11 mice. Error bar means SEM. HR, Heart rate; PR, PR interval; QRS, QRS duration; QTc, corrected QT interval; ms, millisecond; BPM, beats per minute.

set to 1 minute, lead II, and QRS maximum in the LabChart7 software. PR interval, QRS duration, and QT interval were calculated from the average ECG measurements and QT intervals were corrected for RR interval according to Bazett's formula, $\mathrm{QTc}=\mathrm{QT} /(\mathrm{RR} / 100)^{1 / 2}($ Mitchell et al., 1998).

\section{RESULTS}

\section{ECG values are stable over the measuring time}

Mice anesthetized with avertin were measured for ECG 

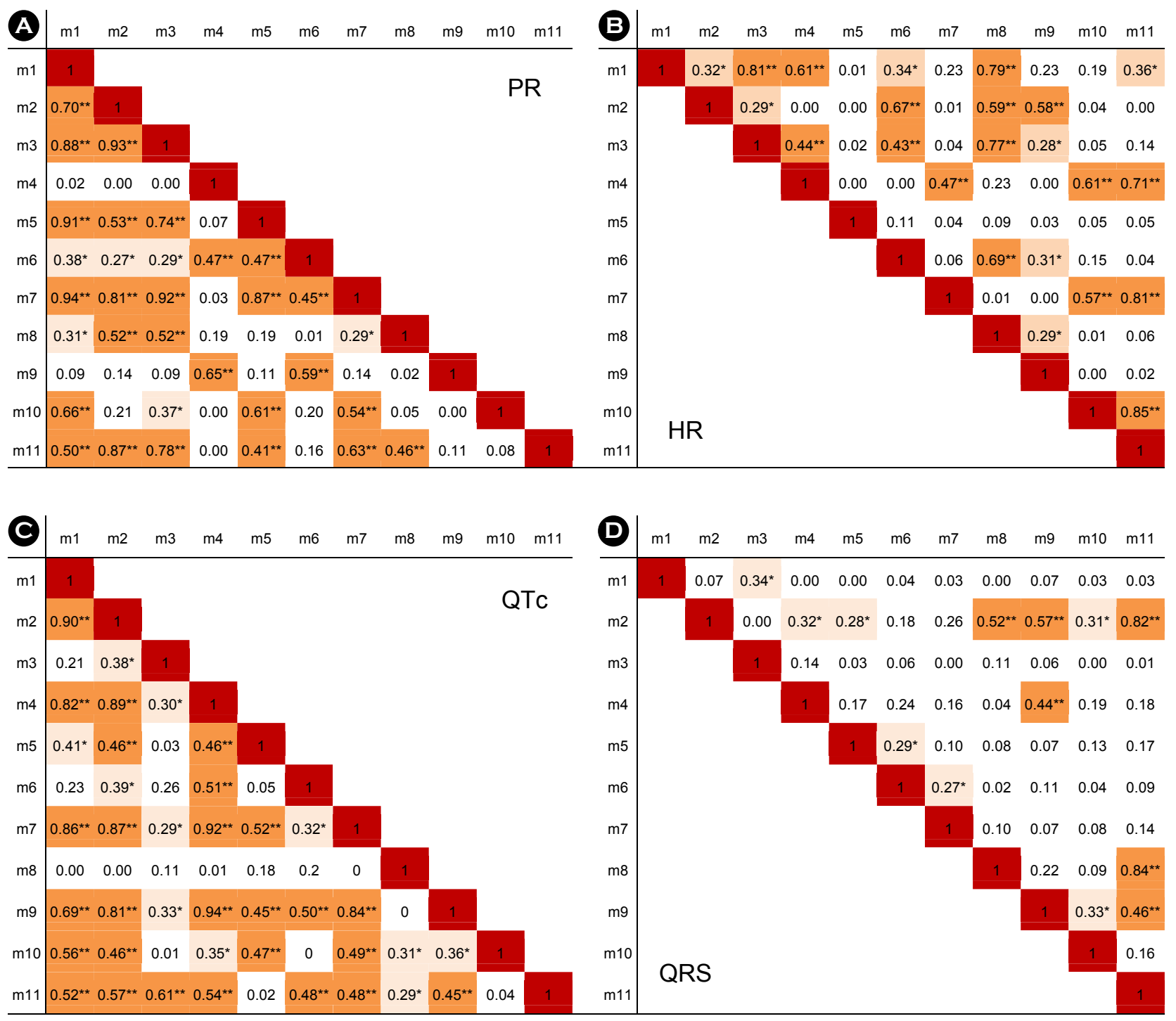

Fig. 3. Correlation plots of ECG parameters among 11 the mice. Each value and background color represented the square of the Pearson's correlation coefficient $\left(r^{2}\right)$ and statistical significance. (A) PR interval; (B) Heart rate; (C) corrected QT interval; (D) QRS duration; m1-m11, mouse \#1 - mouse \# 11; red, $r^{2}=1$; orange and ${ }^{* *}, P<0.001$; light orange and *, $P<0.05$, white, $P \geq 0.05$

over the 15 minutes post-anesthesia (Fig. 2). The heart rate (beats per minute, BPM) on individual mouse was calculated from total beats of the 15 minutes, and the average heart rate among the 11 measured mice was $400.42 \pm 14.43$ BPM (Table 1). Fig. 3B represents the correlation of heart rate among the 11 mice. The heart rate calculated from measurement for 1 minute, 5 minutes, 10 minutes, and 15 minutes were compared with each other using the KruskalWallis test. There was no statistical difference among the measurements, suggesting that recording less than 15 minutes is enough to measure the ECG (Table 1). PR interval, QRS duration, and QTc were also calculated in a similar way and their values were $43.84 \pm 1.54,9.44 \pm 0.17$ and $55.02 \pm 2.16$, respectively (Table 1). Fig. 3A, Fig. $3 \mathrm{C}$ and Fig. 3D represents the correlations of PR interval, QTc, and QRS duration, respectively. Kruskal-Wallis test among measurements for 1, 5, 10,15 minutes did not show any statistical difference in PR interval, QRS duration, and QTc (Table 1). Therefore we decided to record ECG only for 5 minutes, and measurements during the time were used for 
Table 1. ECG measurements in Balb/c mice during 15 minutes

\begin{tabular}{lcccc}
\hline \hline & HR & PR & QRS & QTc \\
\hline 1 min. & $417.17 \pm 14.36$ & $41.13 \pm 1.16$ & $9.05 \pm 0.18$ & $51.65 \pm 1.63$ \\
5 min. & $409.17 \pm 15.27$ & $42.26 \pm 1.29$ & $9.22 \pm 0.18$ & $52.26 \pm 1.86$ \\
10 min. & $404.10 \pm 15.49$ & $43.12 \pm 1.37$ & $9.33 \pm 0.17$ & $53.74 \pm 2.06$ \\
15 min. & $400.42 \pm 14.43$ & $43.84 \pm 1.54$ & $9.44 \pm 0.17$ & $55.02 \pm 2.16$ \\
\hline$P$-value & 0.82 & 0.43 & 0.30 & 0.37 \\
\hline
\end{tabular}

All data are presented as mean \pm SEM. *Statistical significance is evaluated by Kruskal-Wallis test. HR, Heart rate; PR, PR interval; QRS, QRS duration; QTc, corrected QT interval; min., minute

(A)

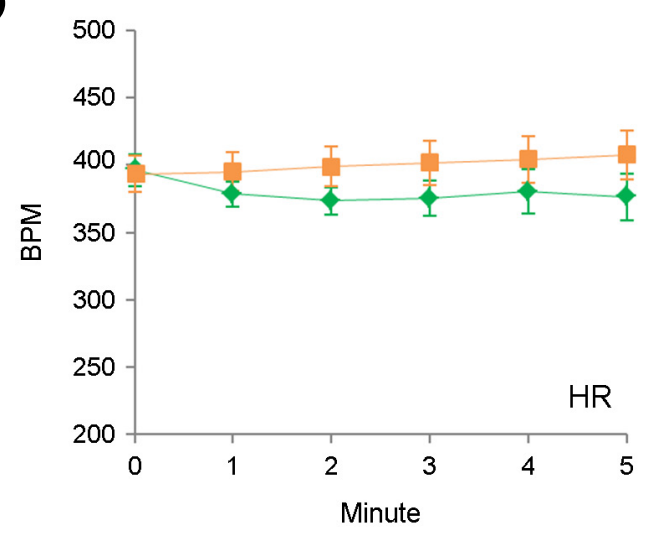

C

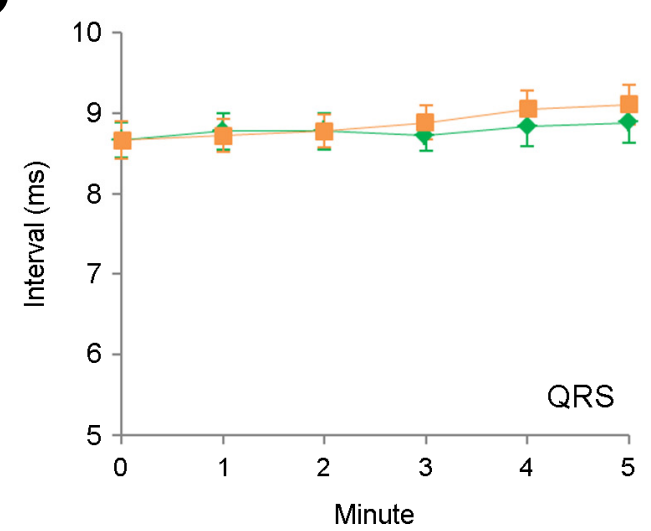

B

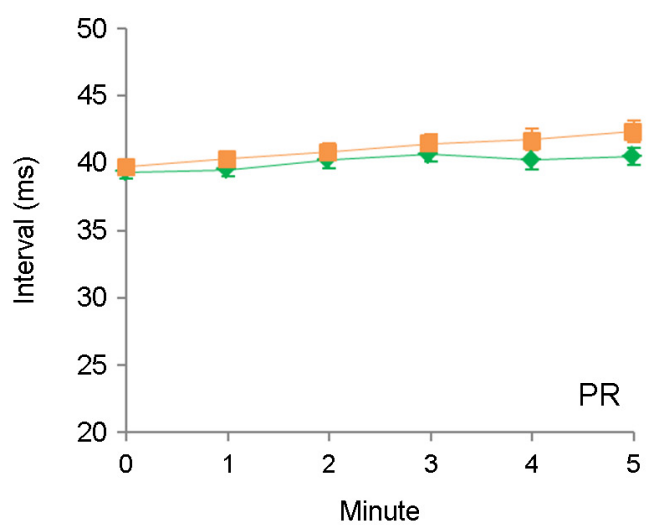

D

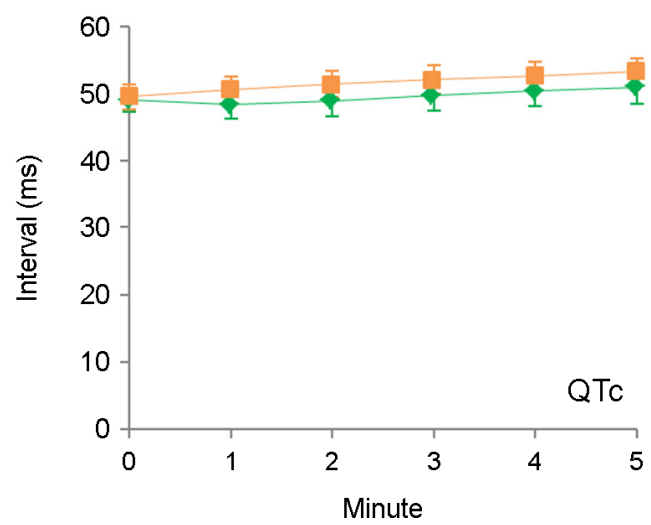

Fig. 4. Repetitive measurements of ECG in the same mouse (6-hr interval). (A) Heart rate; (B) PR interval; (C) QRS duration; (D) corrected QT interval; green line, 1st measurement; orange line, 2nd measurement; Error bar means SEM.

the calculation of heart rate, PR interval, QRS duration, and QTc in the following study.

\section{ECG values are replicated in the same mouse}

The same mouse was measured twice in order to confirm the reproducibility of this method. The second ECG mea- 
Table 2. Repetitive measurements of ECG in the same mouse (6-hr interval)

\begin{tabular}{lcccc}
\hline \hline & HR & PR & QRS & QTc \\
\hline $1^{\text {st }}$ & $417.17 \pm 14.36$ & $41.13 \pm 1.16$ & $9.05 \pm 0.18$ & $51.65 \pm 1.63$ \\
$2^{\text {nd }}$ & $400.42 \pm 14.43$ & $43.84 \pm 1.54$ & $9.44 \pm 0.17$ & $55.02 \pm 2.16$ \\
\hline$P$-value $^{*}$ & 0.14 & 0.26 & 0.80 & 0.09
\end{tabular}

All data presented as mean \pm SEM. $*$ Statistical significance is evaluated by Willcoxon signed rank test. $1^{\text {st }}, 1^{\text {st }}$ measurement; $2^{\text {nd }}, 2^{\text {nd }}$ measurement; HR, Heart rate; PR, PR interval; QRS, QRS duration; QTc, corrected QT interval.

Table 3. ECG comparison of Balb/c and FVB mice

\begin{tabular}{lccc}
\hline \hline ECG trait & $\begin{array}{c}\text { Balb/c } \\
(\mathrm{n}=11)\end{array}$ & $\begin{array}{c}\text { FVB } \\
(\mathrm{n}=13)\end{array}$ & $P$-value \\
\hline HR & $304.8 \pm 6.4$ & $398.4 \pm 6.9$ & $5.67 \mathrm{E}-06$ \\
PR & $44.34 \pm 1.33$ & $37.79 \pm 0.96$ & $7.07 \mathrm{E}-04$ \\
QRS & $9.7 \pm 0.2$ & $10.2 \pm 0.2$ & 0.119 \\
QTc & $48.77 \pm 1.39$ & $42.82 \pm 0.92$ & 0.002 \\
\hline
\end{tabular}

All data presented as mean \pm SEM. *Statistical significance is evaluated by Mann-Whitney U-test. HR, Heart rate; PR, PR interval; QRS, QRS duration; QTc, corrected QT interval

surement was performed 6 hours after the first measurement. The results obtained from 9 mice are shown in Fig. 4. Between two measurements there was no statistical difference in any ECG values including heart rate by using Willcoxon signed rank test (Table 2).

\section{Validation test in Balb/c and FVB mouse strains}

Previously, ECG recordings in Balb/c and FVB mouse strains were reported in conscious mice using radiotelemetry (Shah et al., 2010). These two mouse strains showed significant difference in heart rate and PR interval. Therefore these two mouse strains were investigated for ECG in order to validate the method used in this study. Significant differences were found in heart rate, PR interval and corrected QT interval between $\mathrm{BALB} / \mathrm{c}$ and FVB mouse strains (Table 3 and Fig. 5). Similar to the previous results using radiotelemetry, FVB showed higher heart rate, shorter PRinterval, and shorter corrected QT interval compared to those in Balb/c mouse.
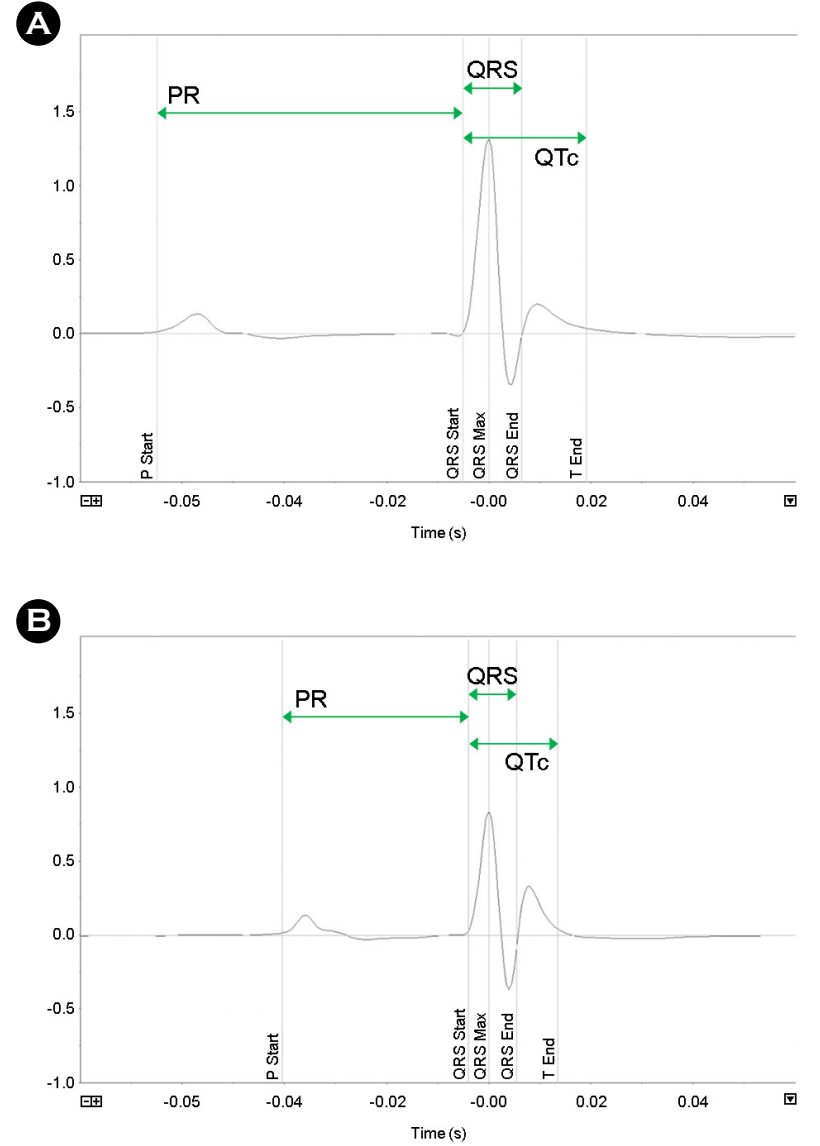

Fig. 5. Comparison of the ECG between Balb/c and FVB mice. The average views were obtained by averaging all ECG complexes during 5 minutes. The $\mathrm{x}$-axis and $\mathrm{y}$-axis presented time (second) and $\mathrm{mV}$ (millivolt). Green arrows indicated duration of PR, QRS and QTc. (A) Balb/c; (B) FVB

\section{DISCUSSION}

Unfortunately we did not compare the ECG measurements upon diverse anesthetic treatments in order to provide 
the strength of avertin over other anesthetics. However, the ECG recordings from mice anesthetized with avertin were stable over the 15 minutes post-anesthesia and reproducible in the same mouse. Avertin has been proved to be a reliable anesthetic, especially for a short-period time in small animals such as mice and because it is not classified as a narcotic drug, it has an advantage for availability (Hart et al., 2001; Roth et al., 2002). Invasive measurement using radiotelemetry has been more widely used compared to non-invasive methods, mostly because of the accuracy and the mouse consciousness during the recording. However, this study partially proved that non-invasive method also could provide the accuracy and reproducibility. Eleven mice were measured with the same non-invasive method and no statistical difference among them was found in any ECG measurements. In addition, repeat measurement in the same mouse was performed in 9 sets of experiment and the results indicated that non-invasive method was reliable for the reproducibility. Further it was shown that measurements for 1, 5, 10, and 15 minutes were not different so that a short recording such as 5 minutes was enough to estimate the ECG values including heart rate.

Non-invasive method has several advantages such as convenience, absence of surgical procedures and speediness of measurement. Therefore non-invasive method may be appropriate to screen for genes affecting the ECG as well as the cardio medicine development. Actually in the laboratory this method has been actively used to identify the causative genes of genetic loci in the genome-wide association study about PR interval, QRS duration and QT interval. The experiment includes the siRNA in vivo delivery system that reduces the gene expression level temporally. Therefore the change of ECG has to be measured shortly after the siRNA injection. Recent genetic studies such as genome-wide association studies could increase the understanding of genetic architecture controlling the heart cycle. As a means to an end, non-invasive method needs to be verified and improved. This is the key rationale for the current study.

In this study, a non-invasive ECG measurement method using three probes including one earth for lead II was tested for the stability during the recording and reproducibility in the same mice anesthetized by avertin. Further this method was validated by measuring the ECG of two different mouse strains, Balb/c and FVB that were previously shown exhibit different ECG values by radiotelemetry. Based on these results, the non-invasive ECG recordings of lead II is recommended as a useful method for quick test in mouse model.

\section{Acknowledgements}

This research was supported by the Basic Science Research Program through the National Research Foundation of Korea (NRF), funded by the Ministry of Education, Science and Technology [NRF-2013R1A1A2012069].

\section{Conflict of interest}

No potential conflict of interest relevant to this article was reported.

\section{REFERENCES}

Bigger JT Jr, Fleiss J, Steinman RC, Rolnitzky LM, Kleiger RE, Rottman JN. Frequency domain measures of heart period variability and mortality after myocardial infarction. Circulation. 1992. 85: 164-171.

Bruell JH, Daroczy AF, Hellerstein HK. Strain and sex differences in serum cholesterol levels of mice. Science. 1962. 135: 1071 -1072 .

de Bruyne MC, Hoes AW, Kors JA, Hofman A, van Bemmel JH, Grobbee DE. Prolonged QT interval predicts cardiac and all-cause mortality in the elderly. The Rotterdam Study. Eur Heart J. 1999. 20: 278-284.

Erhardt W, Hebestedt A, Aschenbrenner G, Pichotka B, Blumel G. A comparative study with various anesthetics in mice (pentobarbitone, ketamine-xylazine, carfentanyl-etomidate). Res Exp Med (Berl). 1984. 184: 159-169.

Gao S, Ho D, Vatner DE, Vatner SF. Echocardiography in mice. Curr Protoc Mouse Biol. 2011. 1: 71-83.

Goldbarg AN, Hellerstein HK, Bruell JH, Daroczy AF. Electrocardiogram of the normal mouse, Mus musculus: general considerations and genetic aspects. Cardiovasc Res. 1968. 2: 93-99.

Hart CY, Burnett JC Jr, Redfield MM. Effects of avertin versus xylazine-ketamine anesthesia on cardiac function in normal mice. Am J Physiol Heart Circ Physiol. 2001. 281: H1938 
$-\mathrm{H} 1945$.

Holm H, Gudbjartsson DF, Arnar DO, Thorleifsson G, Thorgeirsson

G, Stefansdottir H, Gudjonsson SA, Jonasdottir A, Mathiesen EB, Njolstad I, Nyrnes A, Wilsgaard T, Hald EM, Hveem K, Stoltenberg C, Lochen ML, Kong A, Thorsteinsdottir U, Stefansson K. Several common variants modulate heart rate, PR interval and QRS duration. Nat Genet. 2010. 42: 117-122.

Hong KW, Lim JE, Kim JW, Tabara Y, Ueshima H, Miki T, Matsuda F, Cho YS, Kim Y, Oh B. Identification of three novel genetic variations associated with electrocardiographic traits (QRS duration and PR interval) in East Asians. Hum Mol Genet. 2014. 23: 6659-6667.

Janse MJ, Opthof T, Kleber AG. Animal models of cardiac arrhythmias. Cardiovasc Res. 1998. 39: 165-177.

Kim JW, Hong KW, Go MJ, Kim SS, Tabara Y, Kita Y, Tanigawa T, Cho YS, Han BG, Oh B. A common variant in SLC8A1 is associated with the duration of the electrocardiographic QT interval. Am J Hum Genet. 2012. 91: 180-184.

Kleiger RE, Miller JP, Bigger JT Jr, Moss AJ. Decreased heart rate variability and its association with increased mortality after acute myocardial infarction. Am J Cardiol. 1987. 59: 256-262.

Lorenz JN. A practical guide to evaluating cardiovascular, renal, and pulmonary function in mice. Am J Physiol Regul Integr Comp Physiol. 2002. 282: R1565-R1582.

Mitchell GF, Jeron A, Koren G. Measurement of heart rate and Q-T interval in the conscious mouse. Am J Physiol. 1998. 274: H747-H751.

Montanez A, Ruskin JN, Hebert PR, Lamas GA, Hennekens CH. Prolonged QTc interval and risks of total and cardiovascular mortality and sudden death in the general population: a review and qualitative overview of the prospective cohort studies. Arch Intern Med. 2004. 164: 943-948.

Newton-Cheh C, Eijgelsheim M, Rice KM, de Bakker PI, Yin X, Estrada K, Bis JC, Marciante K, Rivadeneira F, Noseworthy PA, Sotoodehnia N, Smith NL, Rotter JI, Kors JA, Witteman JC, Hofman A, Heckbert SR, O'Donnell CJ, Uitterlinden AG, Psaty BM, Lumley T, Larson MG, Stricker BH. Common variants at ten loci influence QT interval duration in the QTGEN Study. Nat Genet. 2009. 41: 399-406.

Odashima M, Usui S, Takagi H, Hong C, Liu J, Yokota M, Sadoshima J. Inhibition of endogenous Mstl prevents apoptosis and cardiac dysfunction without affecting cardiac hypertrophy after myocardial infarction. Circ Res. 2007. 100: 1344-1352.

Pfeufer A, Sanna S, Arking DE, Muller M, Gateva V, Fuchsberger C, Ehret GB, Orru M, Pattaro C, Kottgen A, Perz S, Usala G,
Barbalic M, Li M, Putz B, Scuteri A, Prineas RJ, Sinner MF, Gieger C, Najjar SS, Kao WH, Muhleisen TW, Dei M, Happle C, Mohlenkamp S, Crisponi L, Erbel R, Jockel KH, Naitza S, Steinbeck G, Marroni F, Hicks AA, Lakatta E, Muller-Myhsok B, Pramstaller PP, Wichmann HE, Schlessinger D, Boerwinkle E, Meitinger T, Uda M, Coresh J, Kaab S, Abecasis GR, Chakravarti A. Common variants at ten loci modulate the QT interval duration in the QTSCD Study. Nat Genet. 2009. 41: 407-414.

Pfeufer A, van Noord C, Marciante KD, Arking DE, Larson MG, Smith AV, Tarasov KV, Muller M, Sotoodehnia N, Sinner MF, Verwoert GC, Li M, Kao WH, Kottgen A, Coresh J, Bis JC, Psaty BM, Rice K, Rotter JI, Rivadeneira F, Hofman A, Kors JA, Stricker BH, Uitterlinden AG, van Duijn CM, Beckmann BM, Sauter W, Gieger C, Lubitz SA, NewtonCheh C, Wang TJ, Magnani JW, Schnabel RB, Chung MK, Barnard J, Smith JD, Van Wagoner DR, Vasan RS, Aspelund T, Eiriksdottir G, Harris TB, Launer LJ, Najjar SS, Lakatta E, Schlessinger D, Uda M, Abecasis GR, Muller-Myhsok B, Ehret GB, Boerwinkle E, Chakravarti A, Soliman EZ, Lunetta KL, Perz S, Wichmann HE, Meitinger T, Levy D, Gudnason V, Ellinor PT, Sanna S, Kaab S, Witteman JC, Alonso A, Benjamin EJ, Heckbert SR. Genome-wide association study of PR interval. Nat Genet. 2010. 42: 153-159.

Roth DM, Swaney JS, Dalton ND, Gilpin EA, Ross J Jr. Impact of anesthesia on cardiac function during echocardiography in mice. Am J Physiol Heart Circ Physiol. 2002. 282: H2134 $-\mathrm{H} 2140$.

Sandercock GR, Brodie DA. The role of heart rate variability in prognosis for different modes of death in chronic heart failure. Pacing Clin Electrophysiol. 2006. 29: 892-904.

Shah AP, Siedlecka U, Gandhi A, Navaratnarajah M, Al-Saud SA, Yacoub MH, Terracciano CM. Genetic background affects function and intracellular calcium regulation of mouse hearts. Cardiovasc Res. 2010. 87: 683-693.

Sotoodehnia N, Isaacs A, de Bakker PI, Dorr M, Newton-Cheh C, Nolte IM, van der Harst P, Muller M, Eijgelsheim M, Alonso A, Hicks AA, Padmanabhan S, Hayward C, Smith AV, Polasek O, Giovannone S, Fu J, Magnani JW, Marciante KD, Pfeufer A, Gharib SA, Teumer A, Li M, Bis JC, Rivadeneira F, Aspelund T, Kottgen A, Johnson T, Rice K, Sie MP, Wang YA, Klopp N, Fuchsberger C, Wild SH, Mateo Leach I, Estrada K, Volker U, Wright AF, Asselbergs FW, Qu J, Chakravarti A, Sinner MF, Kors JA, Petersmann A, Harris TB, Soliman EZ, Munroe PB, Psaty BM, Oostra BA, Cupples LA, Perz S, de 
Boer RA, Uitterlinden AG, Volzke H, Spector TD, Liu FY, Boerwinkle E, Dominiczak AF, Rotter JI, van Herpen G, Levy D, Wichmann HE, van Gilst WH, Witteman JC, Kroemer HK, Kao WH, Heckbert SR, Meitinger T, Hofman A, Campbell H, Folsom AR, van Veldhuisen DJ, Schwienbacher C, O'Donnell CJ, Volpato CB, Caulfield MJ, Connell JM, Launer L, Lu X, Franke L, Fehrmann RS, te Meerman G, Groen HJ, Weersma RK, van den Berg LH, Wijmenga C, Ophoff RA, Navis G, Rudan I, Snieder H, Wilson JF, Pramstaller PP, Siscovick DS, Wang TJ, Gudnason V, van Duijn CM, Felix SB, Fishman GI, Jamshidi Y, Stricker BH, Samani NJ, Kaab S, Arking DE. Common variants in 22 loci are associated with QRS duration and cardiac ventricular conduction. Nat Genet. 2010. 42: 1068 -1076 .

Stypmann J. Doppler ultrasound in mice. Echocardiography. 2007. 24: 97-112.
Uechi M, Asai K, Osaka M, Smith A, Sato N, Wagner TE, Ishikawa Y, Hayakawa H, Vatner DE, Shannon RP, Homcy CJ, Vatner SF. Depressed heart rate variability and arterial baroreflex in conscious transgenic mice with overexpression of cardiac Gsa. Circ Res. 1998. 82: 416-423.

Xu Q, Ming Z, Dart AM, Du XJ. Optimizing dosage of ketamine and xylazine in murine echocardiography. Clin Exp Pharmacol Physiol. 2007. 34: 499-507.

Yang XP, Liu YH, Rhaleb NE, Kurihara N, Kim HE, Carretero OA. Echocardiographic assessment of cardiac function in conscious and anesthetized mice. Am J Physiol. 1999. 277 H1967-H1974.

Zhao X, Ho D, Gao S, Hong C, Vatner DE, Vatner SF. Arterial pressure monitoring in mice. Curr Protoc Mouse Biol. 2011. 1: 105-122. 